$44(2) \mid 2015$

Varia

Bogotá, 22 de junio-3 de julio de 2015

\title{
Escuela Internacional 2015: «Del conocimiento tradicional al científico y del científico a la sociedad»
}

Bogotá, 22 de junio-3 de julio de 2015

Céline Valadeau

\section{(2) OpenEdition}

Journals

Edición electrónica

URL: http://journals.openedition.org/bifea/7609

DOI: $10.4000 /$ bifea.7609

ISSN: 2076-5827

Editor

Institut Français d'Études Andines

Edición impresa

Fecha de publicación: 1 agosto 2015

Paginación: 298-300

ISSN: 0303-7495

\section{Referencia electrónica}

Céline Valadeau, «Escuela Internacional 2015: «Del conocimiento tradicional al científico y del

científico a la sociedad» », Bulletin de l'Institut français d'études andines [En línea], 44 (2) | 2015,

Publicado el 08 agosto 2015, consultado el 06 noviembre 2020. URL : http://journals.openedition.org/ bifea/7609 ; DOI : https://doi.org/10.4000/bifea.7609

\section{cc) (†) $\odot$}

Les contenus du Bulletin de l'Institut français d'études andines sont mis à disposition selon les termes de la licence Creative Commons Attribution - Pas d'Utilisation Commerciale - Pas de Modification 4.0 International. 


\title{
ESCUELA INTERNACIONAL 2015: «DEL CONOCIMIENTO TRADICIONAL AL CIENTÍFICO Y DEL CIENTÍFICO A LA SOCIEDAD»
}

\author{
Bogotá, 22 de junio-3 de julio de 2015
}

Cada año y durante unos meses, la Escuela Internacional presenta cinco series de cursos seleccionados. Este evento pretende ser un espacio promocionado por la Universidad Nacional de Colombia-sede Bogotá para contribuir a que los temas de vanguardia promuevan la investigación y ayuden a que la Universidad Nacional se transforme en una institución de interés para investigadores, docentes y profesionales en general a nivel nacional e internacional.

El objetivo global es fomentar y difundir la investigación, las actividades propiamente académicas y sus desarrollos temáticos a nivel nacional e internacional como resultado de la participación de la Comunidad Académica y expertos de distintas áreas del conocimiento.

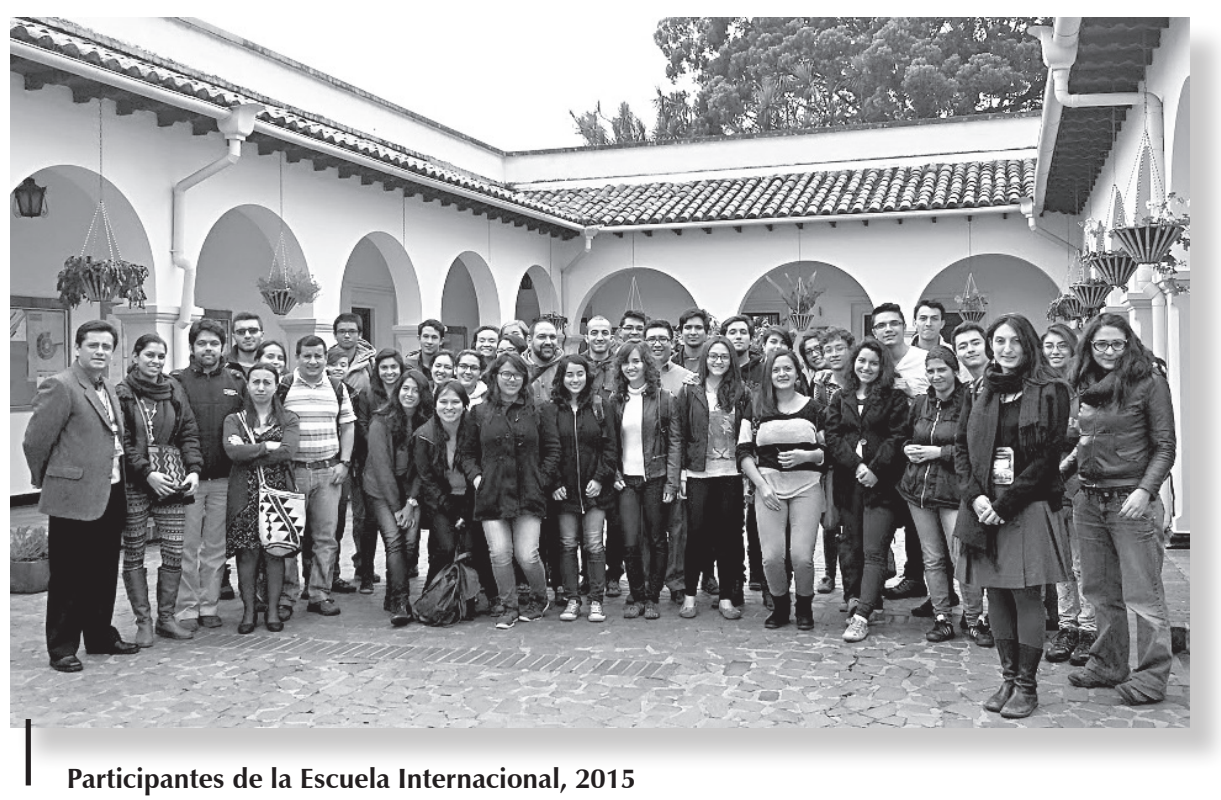

(C) Yohanna Lara

Los objetivos específicos son varios. En primer lugar, busca crear un espacio de encuentro entre distintas disciplinas científicas de la Comunidad Académica. También quiere constituir relaciones académicas que permitan la movilidad e integración de profesionales, docentes e investigadores a nivel internacional. El tercer objetivo es promover el desarrollo e interacción de temáticas y ejes de investigación que respondan a necesidades propias de la sociedad. Además, quiere desarrollar un espacio que contribuya a la internacionalización de la sede Bogotá. Para terminar, el último objetivo es fomentar el uso de una segunda lengua que permita el desarrollo de competencias en la comunidad académica. 
En el marco del programa de la Escuela Internacional 2015, el IFEA de Bogotá se asoció a la Facultad de Ciencia de la Universidad Nacional para impulsar una serie de cursos con un enfoque central: la planta y su uso. El reto era abordar conceptos básicos de etnobotánica, etnofarmacología, biodiversidad, acceso a recursos genéticos y conocimiento tradicional del medio ambiente.

El evento se desarrolló en el auditorio de la Facultad de Ciencias del 22 de junio al 3 de julio de 2015. El curso duró 64 horas y se realizó una visita a los jardines de hierbas medicinales del Jardín Botánico José Celestino Mutis de Bogotá y del Herbario Nacional de Colombia (COL) del Instituto Nacional de Ciencias Naturales. Para las presentaciones de los cursos, fue aprobado un cupo de 65 estudiantes de pregrado y posgrado, profesores e investigadores. Este evento científico permitió contar con la presencia de ocho profesores e investigadores internacionales y siete nacionales.

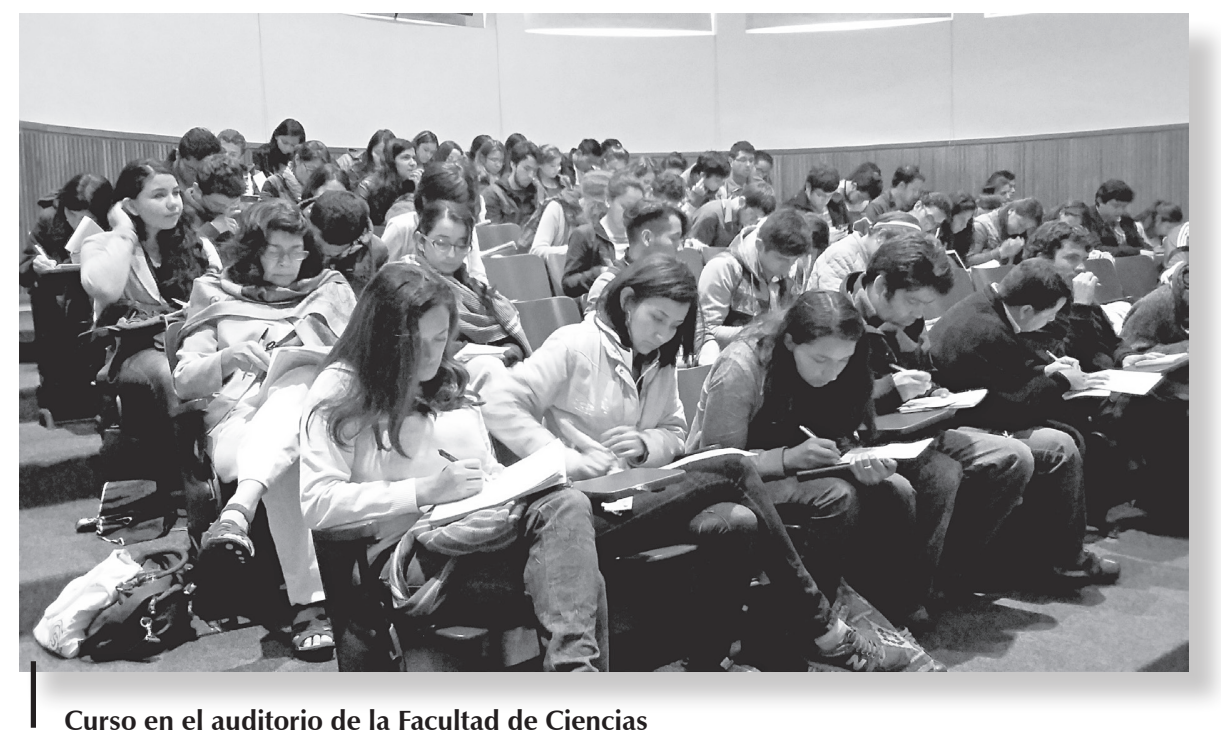

(C) Yohanna Lara

Las presentaciones fueron divididas en dos ejes principales. El primero se interesó en las nociones de «sabiduría, sociedades y plantas» en América Latina y el segundo desarrolló el tema de «valorización de las distintas biodiversidades». Los cursos fueron pensados a manera de una cadena lógica que podría ser imaginada como un proceso de consideración de la naturaleza. Dicho de otro modo, el interés se enfocó en el conocimiento del medio ambiente por diferentes grupos étnicos, la sabiduría llevada por las plantas y las ciencias de sus usos respectivos. En un sentido y para dar una imagen de lo que ha sucedido, la reflexión se centró alrededor de historias y dichos similares a lo que sigue:

En las orillas de las lagunas, Tityre iba a colectar las plantas útiles. Él encuentra borrajas, malvaviscos eficaces y centaureas muy amargas. Regresa con un ramo de plantas. Conocedor de la virtud de las plantas, busca gente para 
curar. Alrededor de las lagunas, nadie. Piensa: iqué lastima! Entonces se va hacia las salinas donde están las fiebres y los obreros. Se dirige hacia ellos, les habla, les demuestra que están enfermos; pero uno dice que no lo está; otro, a quien Tityre dio una flor medicinal, la pone en un florero para verla crecer; $y$ finalmente uno que sabe que tiene fiebre, pero que piensa que es beneficioso para la salud.

Y como nadie quiso sanarse y que las flores iban a marchitarse, Tityre toma él mismo la fiebre para poder al menos curarse... (Gide, 1895)1.

Para llevar a cabo este importante programa, distintas disciplinas fueron convocadas. Eso permitió tratar de manera pluridisciplinaria temas que tienen por costumbre ser pensados individualmente. Durante la primera semana, se diseñaron los marcos teóricos y metodológicos de las investigaciones, para luego, la segunda semana, interesarse en diferentes estudios de casos de la Amazonía colombiana, brasileña, peruana y guyanesa y, también, de la cordillera de los Andes. Así, la biodiversidad biológica y cultural fue abordada desde los puntos de vista de la Antropología, de la Etnología, de la Botánica, de la Medicina y del Derecho.

\section{Referencia citada}

GIDE, A., 1895 - Paludes, 103 pp.; París: L’Art Indépendant. 